\title{
Geographic information systems (GIS)-based spatially distributed model for runoff routing
}

\author{
Francisco Olivera and David Maidment \\ Center for Research in Water Resources, J. J. Pickle Research Campus, University of Texas at Austin
}

\begin{abstract}
A method is proposed for routing spatially distributed excess precipitation over a watershed to produce runoff at its outlet. The land surface is represented by a (raster) digital elevation model from which the stream network is derived. A routing response function is defined for each digital elevation model cell so that water movement from cell to cell can be convolved to give a response function along a flow path and responses from all cells can be summed to give the outlet hydrograph. An example application of analysis of runoff on Waller Creek in Austin, Texas, is presented.
\end{abstract}

\section{Introduction}

In rainfall-runoff computation, not only is the generation of excess precipitation spatially distributed, but also the precipitation itself, which limits the use of the unit hydrograph model. The theory presented in this paper is an attempt to generalize the unit hydrograph method for runoff response and to do so on a spatially distributed basis in which the runoff responses from subareas of the watershed are considered separately instead of being spatially averaged. The need for scaleindependent flow routing parameters for calculating flow time (flow velocity) and spreading of a mass slug around its centroid because of shear effects (dispersion coefficient) is presented in this paper. The use of these parameters for better estimation of hydrographs is also explained.

Although the theory of linear routing systems is not bound to raster representations of a study area, the model proposed here is based on raster or grid data structures. A grid data structure is a discrete representation of the terrain based on identical square cells arranged in rows and columns. Grids are used to describe spatially distributed terrain parameters (i.e., elevation, land use, impervious cover, etc.), and one set of grid values is necessary for each represented. The density of grid cells should be large enough to resemble the continuous character of the terrain.

Starting from the digital elevation model (DEM), hydrologic features of the terrain (i.e., flow direction, flow accumulation, flow length, stream network, and drainage areas) can be determined using standard functions included in commercially available geographic information systems (GIS) software that operates on raster terrain data. DEMs are available with a resolution of $30^{\prime \prime}(\sim 1 \mathrm{~km})$ for the entire Earth, 3" $(\sim 90 \mathrm{~m})$ for the United States, and various resolutions for other countries. Using the flow direction GIS function, a single downstream cell, in the direction of the steepest descent, can be defined for each DEM cell, so that a unique connection from each cell to the watershed outlet can be determined. This process produces a cell network, with the shape of a spanning tree, that represents the paths of the watershed flow system. Flow routing consists of tracking the water throughout the cell network.

A two-parameter routing response function is determined

Copyright 1999 by the American Geophysical Union.

Paper number 1998WR900104.

0043-1397/99/1998WR900104\$09.00 for each cell, in which the parameters are related to flow time (flow velocity) and to shear effects (dispersion coefficient) in the cell. Flow path response functions, responses at the outlet to instantaneous unit inputs in the cells, are calculated by convolving the responses of the cells located within the reach. The watershed response is obtained as the sum of the flow path responses to a spatially distributed precipitation excess.

\section{Literature Review}

Pilgrim [1976] carried out an experimental study which involved tracing flood runoff from specific points of a $0.39 \mathrm{~km}^{2}$ watershed, near Sydney, Australia, and measuring the travel time of the labeled particles to the outlet. A conclusion of his study is that [Pilgrim, 1976, p. 493] "at medium to high flows the travel times and average velocities become almost constant, indicating that linearity is approximated at this range of flows." Additionally, according to him, for a watershed subdivided into nonoverlapping subareas, linearity of the routing system implies that the overall watershed response is equal to the sum of the responses of its subareas. This is an important insight when dealing with spatial variability of the watershed.

An attempt to link the geomorphological characteristics with the hydrologic response of a watershed is given by RodriguezIturbe and Valdes [1979]. In their paper, Horton's empirical laws, i.e., law of stream numbers, lengths, and areas, are used to describe the geomorphology of the system.

Mesa and Mifflin [1986], Naden [1992], and Troch et al. [1994] present similar methodologies to account for spatial variability when determining the watershed response. The catchment response is calculated as the convolution of a network response and a hillslope response. The network response is calculated as the solution of the advection-dispersion equation weighted according to the width function of the network, which is equal to the number of stream branches as a function of distance from the watershed outlet. The studies present no physically based methodology to determine the hillslope response.

An interesting approach to model the fast and slow responses of a catchment is presented by Littlewood and Jakeman [1992, 1994]. In their model the watershed is idealized as two linear storage systems in parallel, representing the surface and the subsurface water systems. The surface system is faster and affects mainly the rising limb of the resulting hydrograph, while 
the subsurface system is slow and determines the falling limb of the response.

Spatially variable hydrologic systems require the use of distributed models, rather than lumped models, to fully describe the system. However, because the boundary between lumped and distributed models is not clearly defined, there have been attempts to account for spatially distributed terrain attributes based on lumped models. The Hydrologic Engineering Center (HEC) HEC-1 flood routing package, for example, allows the user to subdivide the watershed into smaller subbasins for analysis purposes and to route their corresponding responses to the watershed outlet. In this case the concept of a purely lumped model does not apply, although HEC-1 is not a fully spatially distributed model either.

Grid-based GIS, in particular, appear to be a very suitable tool for spatially distributed hydrologic modeling, mainly because [Maidment, 1992a, p. 4] "raster systems have been used for digital image processing for decades and a mature understanding and technology has been created for that task." The Environmental Systems Research Institute (ESRI) Arc/InfoGrid system as well as the U.S. Army Corps of Engineers Geographical Resource Analysis Support System (GRASS) work on grid data structures. Grid systems are well suited for modeling gravity driven flow because a characteristic of this type of flow is that flow directions depend entirely on topography and not on any time-dependent variable. At present, hydrologic functions, available in Grid and GRASS, allow one to determine flow direction and drainage area at any location, stream networks, watershed delineation, and other hydrologic properties [Maidment, 1992a].

Recently, there have been attempts to take advantage of GIS capabilities for runoff and nonpoint source pollution modeling. Vieux [1991] presents a review of water quantity and quality modeling using GIS and, as an application example, employs the kinematic wave method to an overland flow problem. In his paper, GIS is used to process the spatially variable terrain, and the finite element method is used to solve the routing equations. Maidment [1992a, b, 1993] presents a gridbased methodology for determining a spatially distributed unit hydrograph based on a time-invariant flow velocity field. According to him the velocity time invariance is a requirement for the existence of a unit hydrograph with a constant time base and relative shape. Maidment obtained a flow time grid and subsequently the isochrone curves and the time-area diagram from a constant velocity field. The unit hydrograph is obtained as the incremental areas of the time-area diagram, assuming a pure translation flow process.

A more elaborate flow model, which accounts for both translation and storage effects in the watershed, is presented by Maidment et al. [1996a]. In this paper the watershed response is calculated as the sum of the responses of each individual grid cell, which is determined as a combined process of channel flow (translation process) followed by a linear reservoir routing (storage process). Olivera et al. [1995] and Olivera and Maidment [1996] present a grid-based, unsteady flow, linear approach that uses the diffusion wave method to model storm runoff and constituent transport. In these articles the routing from each watershed cell to the watershed outlet is calculated by convolving the responses of the grid cells of the drainage path.

Sensitivity of model results to the spatial resolution of the data has been addressed by Vieux [1993], who discusses how the grid cell size affects the estimation of terrain slope and flow path length and, in turn, of surface runoff. Vieux and Needham [1993] conclude that increasing the cell size shortens the stream length and increases the sediment yield of a watershed.

Attempting to account for spatial variability of the terrain in storm runoff modeling, researchers have taken either of the following paths: (1) partitioning the hydrologic system into subsystems and applying lumped models to each of them or (2) developing GIS interfaces to generate input files for other lumped models and displaying the results in the form of a map. In both cases an improvement with respect to the traditional fully lumped models has been accomplished; however, these kinds of solutions cannot be considered spatially distributed. In this research, storm runoff is modeled within GIS, redefining the use of GIS as a modeling tool and not only a link between the heterogeneous terrain and an existing lumped model.

\section{Methodology}

For a spatially uniform hydrologic system the unit hydrograph model states that

$$
Q(t)=A_{w} \int_{0}^{t} I(\tau) \cup(t-\tau) d \tau
$$

where $t[T]$ is time, $Q(t)\left[L^{3} T^{-1}\right]$ is the flow at the watershed outlet, $A_{w}\left[L^{2}\right]$ is the watershed area, $I(t)\left[L T^{-1}\right]$ is the excess precipitation, and $U(t)\left[T^{-1}\right]$ is the watershed response (unit hydrograph). Likewise, for a spatially distributed linear system subdivided into uniform nonoverlapping subareas this equation takes the form of [Maidment et al., 1996a]

$$
Q(t)=\sum_{t=1}^{N_{w}} A_{t} \int_{0}^{t} I_{t}(\tau) U_{t}(t-\tau) d \tau
$$

where $N_{w}$ is the number of subareas, $A_{t}\left[L^{2}\right]$ is the area of subarea $i, I_{\imath}(t)\left[L T^{-1}\right]$ is the excess precipitation intensity in subarea $i$ (subarea input), and $U_{i}(t)\left[T^{-1}\right]$ is the response at the watershed outlet to a unit instantaneous input in subarea $i$. Notice that it is because of the additivity property that characterizes linear systems that the overall watershed response can be calculated as the sum of the subarea responses. From the physical point of view this summation implies that the routing of a subarea input to the watershed outlet is not affected by the routing of other subarea inputs and that all inputs can be routed simultaneously yet independently. The use of (2) requires the excess precipitation $I_{i}(t)$ and the response function $U_{t}(t)$ of each subarea.

In this study the subareas are taken as small square cells that resemble the continuous character of the landscape, and because the number of cells into which the watershed is subdivided defines how well the spatial variability of the system is captured, the accuracy of the model depends on the resolution of the discretization. As an example, Figure 1 shows the raster model of the $10.7 \mathrm{~km}^{2}$ Waller Creek drainage area upstream of 23rd Street, which was subdivided into $11,90030 \mathrm{~m}$ by $30 \mathrm{~m}$ cells. Once the system has been discretized into cells, a flow path is defined as the sequence of cells that connect a specific cell with another cell located downstream (see Figure 2). From the physical point of view, grid cells are short flow paths, which, because of their size, can be considered uniform.

The response at the watershed outlet cell to an instantaneous unit input in an upstream watershed cell is called here 
flow path response function $U_{i}(t)\left[T^{-1}\right]$. Flow path response functions $U_{i}(t)$ represent the translation (advection) and redistribution (dispersion) processes in the flow path, i.e., lag time from the watershed cell to the watershed outlet and spreading around the centroid of the mass element. This approach can also be used to route constituents over a watershed because it considers advection and dispersion in the flow as well as spatial distribution of the constituent sources. Firstorder mass losses of constituents can also be included in the model by adding an exponential decay term in the response function.

Flow path response functions $U_{i}(t)$ must satisfy certain mathematical properties so that if, for example, an input in cell $A$ is routed to cell $B$ and then to cell $C$, the result should be the same as if it were routed directly from $A$ to $C$ (see Figure 3 ). To understand the implications of this condition, notice that the flow path response function $U_{\mathrm{AB}}(t)$ is the probability density function of a random variable $X_{\mathrm{AB}}$ that represents the time spent by a water particle in the flow path that runs from cell $A$ to cell B. Accordingly, $U_{\mathrm{BC}}(t)$ and $U_{\mathrm{AC}}(t)$ are the probability density functions of random variables $X_{\mathrm{BC}}$ and $X_{\mathrm{AC}}$, respectively. Since the time spent in $\mathrm{AC}$ is the sum of the times spent in $\mathrm{AB}$ and $\mathrm{BC}$ it follows that $X_{\mathrm{AB}}+X_{\mathrm{BC}}=X_{\mathrm{AC}}$. In terms of probability density functions this is expressed as

$$
U_{\mathrm{AB}}(t) * U_{\mathrm{BC}}(t)=U_{\mathrm{AC}}(t)
$$

where the asterisk stands for convolution.

Extending the concept of response functions to the cell level allows one to model the flow based on scale-independent ter-

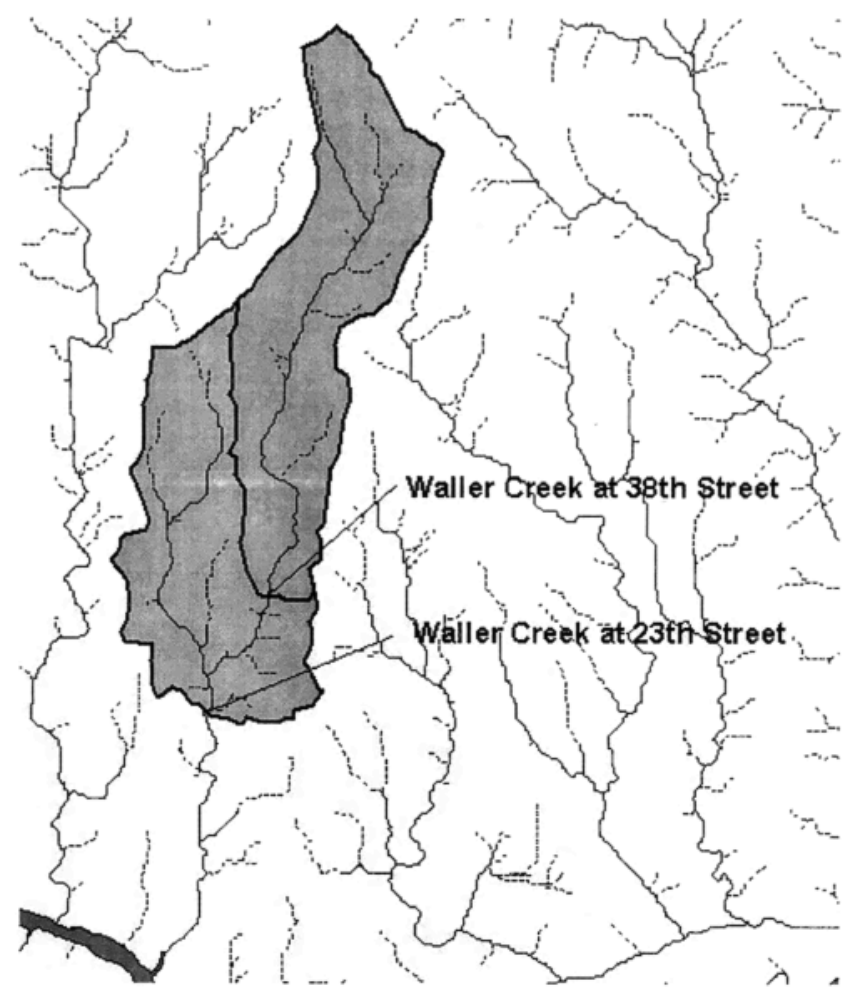

Figure 1. Raster model of Waller Creek at Austin, Texas. The landscape is subdivided into a large number of small square cells that resemble the continuous character of the terrain. The thick solid lines correspond to the watershed boundary, and the thin lines correspond to the cells that drain $90,000 \mathrm{~m}^{2}$ more.

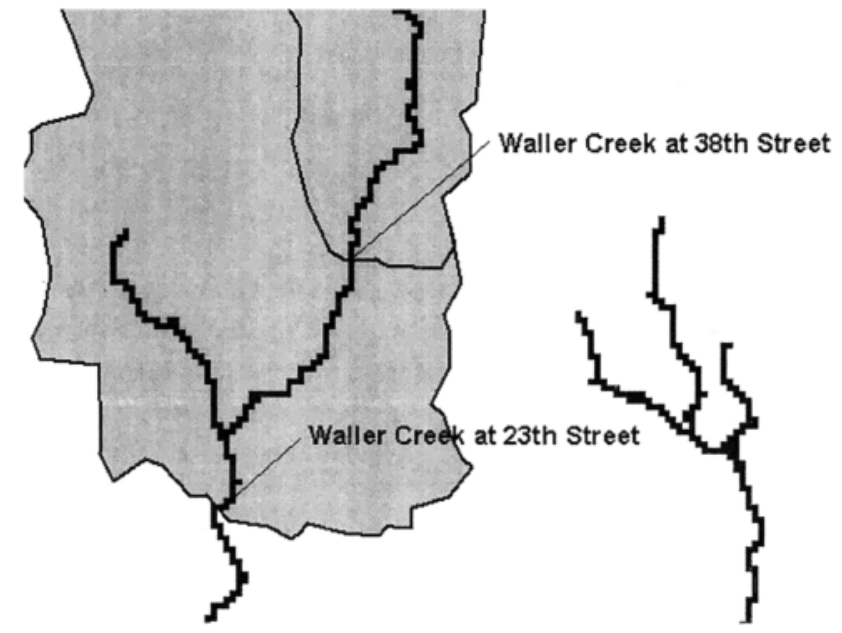

Figure 2. Detail of Waller Creek at Austin, Texas, showing flow paths. A flow path is a sequence of cells that connect two points of the watershed following a streamline.

rain parameters that are defined for each cell, as is discussed below. Since the time spent in a flow path is equal to the sum of the time spent in each of its elementary cells, i.e., $X_{i}=x_{1}+$ $x_{2}+\cdots+x_{N}$, where $X_{l}[T]$ is a random variable that represents the time spent in the flow path and $x_{1}, x_{2}, \cdots$, and $x_{N}$ $[T]$ are random variables that represent the time spent in each of the $N$ cells that form the flow path, it follows that

$$
U_{t}(t)=u_{l}(t)^{*} u_{2}(t)^{*} \ldots{ }^{*} u_{N}(t)
$$

where $U_{t}(t), u_{1}(t), u_{2}(t), \cdots u_{N}(t)\left[T^{-1}\right]$ are the probability density functions of $X_{i}, x_{1}, x_{2}, \cdots$, and $x_{N}$ respectively.

In general, response functions cannot be defined by a finite number of parameters and a table of values, with as many values as information is available, is necessary. However, sometimes representing response functions as statistical distributions (i.e., normal distribution, gamma distribution, firstpassage-time distribution, etc.) responds to the need of modeling a large number of flow elements when not enough data to define each of the responses are available. Representing response functions as statistical distributions also minimizes disk storage, although at the cost of accuracy.

From the physical point of view, if the grid cells are assumed to convey one-dimensional and unsteady flow and the inertial terms in the St. Venant momentum equation are neglected, the flow in the cells can be modeled with the diffusion wave equation [Miller and Cunge, 1975; Lettenmaier and Wood, 1993]. Thus, if lateral inflow is not considered, the flow in cell $i$ is represented by

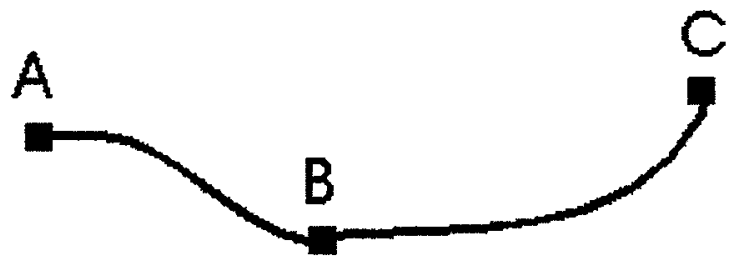

Figure 3. If an input in cell $A$ is routed to cell $B$ and then to cell $C$, the result should be the same as if it were routed directly from $\mathrm{A}$ to $\mathrm{C}$. 


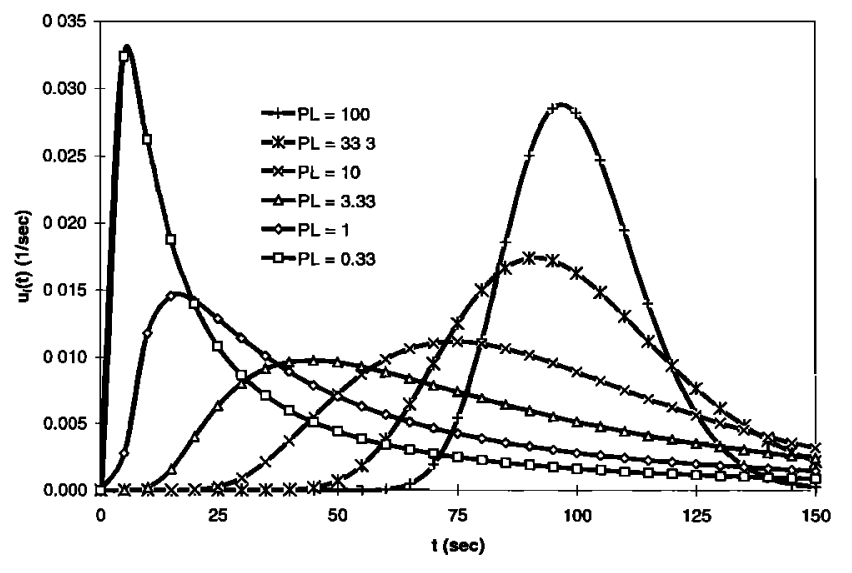

Figure 4. First-passage-time distributions for an expected travel time of $100 \mathrm{~s}$ and different Peclet numbers.

$$
\frac{\partial Q_{t}}{\partial t}+c_{\iota} \frac{\partial Q_{\iota}}{\partial x}-d_{\imath} \frac{\partial^{2} Q_{\iota}}{\partial x^{2}}=0
$$

where $x[L]$ is the distance along the flow direction, $t[T]$ is the time, $Q_{i}\left[L^{3} T^{-1}\right]$ is the flow at any time $t$ and location $x$ of cell $i, c_{1}\left[L T^{-1}\right]$ is the kinematic wave celerity in cell $i$, and $d_{\imath}$ $\left[L^{2} T^{-1}\right]$ is the dispersion coefficient in cell $i$. For a timeinvariant flow velocity $v_{i}$ at each cell $i$ the kinematic wave celerity $c_{t}$ is equal to the flow velocity because $c_{t}=d Q_{t} / d A$ [Chow et al., 1988] and, it follows, $c_{t}=d\left(v_{i} A\right) / d A=v_{i} d(A) / d A=v_{t}$. Time invariance of the flow velocity $v_{i}$ is a property of linear routing systems [Olivera, 1996].

For a unit-impulse input the solution of (5) for $Q_{i}$ at the cell outlet is the cell response function $u_{i}(t)$, which, for a system bounded by a transmitting barrier upstream (open boundary) and an adsorbing barrier downstream (closed boundary), results in a first-passage-time distribution [Nauman, 1981]:

$u_{t}(t)=\frac{1}{2 t \sqrt{\pi\left(t / t_{t}\right) /\left(v_{i} l_{l} / d_{t}\right)}} \exp \left\{-\frac{\left[1-\left(t / t_{i}\right)\right]^{2}}{4\left(t / t_{t}\right) /\left(v_{i} l_{l} / d_{t}\right)}\right\}$

where $t_{i}[T]$ is the expected flow time through the cell and $l_{i}$ $[L]$ is the flow length within the cell, i.e., $l_{t}=v_{t} t_{t}$. Firstpassage-time distributions have previously been used to model the residence time of water in hydrologic systems [Mesa and Mifflin, 1986; Naden, 1992; Troch et al., 1994]. Because the cell flow length $l_{i}$ is known, the only two parameters needed to define $u_{i}(t)$ are the flow velocity $v_{t}$ and the dispersion coefficient $d_{i}$. In some cases it is preferable to define the dimensionless Peclet number $P e_{L}=v_{i} l_{t} / d_{i}$, instead of the dispersion coefficient $d_{\imath}$, to describe the dispersion (shear and storage) effects in the cell. However, it should be noted that because it involves the flow length in its definition, the Peclet number is a scale-dependent parameter. Figure 4 shows first-passagetime distributions for an average travel time $t_{t}=100 \mathrm{~s}$ and different Peclet numbers. Formulas for estimating the flow velocity $v_{i}$ as a function of terrain parameters have been proposed by the Soil Conservation Service (SCS) [1985] and Maidment et al. [1996a] and to calculate the dispersion coefficient $d_{i}$ by Miller and Cunge [1975] and Troch et al. [1994]. However, all these formulas are based on local parameters that are difficult to calculate, especially for the case of overland flow.

The flow path response function is found by convolving the cell response functions as shown in (4). Although different analytical methods for calculating the convolution integral ex- ist (i.e., analytical integration, Laplace transforms, Fourier transforms, etc.), in many cases, analytical solutions cannot be found, and numerical integration has to be used.

Maidment et al. [1996b], for example, used numerical integration for evaluating the convolution of response functions of the subcatchments of the Niger River basin in West Africa. In that case the number of flow elements was 167 , which meant that only 167 convolutions had to be done and that only 167 time series resulting from the convolutions had to be stored. However, in the case of a raster system with a number of flow elements that range from a few thousand to a few million elements $(11,900$ elements for the example presented below), numerical integration might become too time consuming and demanding of disk storage.

Because the use of (4) implies as many convolutions as there are cells in the watershed, an approximate solution to the sequence of convolution integrals along a flow path is proposed here. This approximate solution is a two-parameter distribution that matches the first and second moments of the mathematically correct solution. The main advantage of this approach is that each flow path response consists of only three pieces of information: a two-parameter distribution type and the two parameters of the distribution, which eliminates the problem with calculation time and storage space. Olivera [1996] observed that three-parameter distributions tend to overestimate the importance of the tails with respect to the central part of the distribution. Likewise, it was observed that for equal first and second moments, two-parameter distributions such as normal, gamma, or first-passage-time, do not differ significantly from each other if their skewness (third moment around the mean) is small. Comparison between the approximate solution and the mathematically correct solution, though, is difficult because the mathematically correct solution can be calculated only by numerical integration and therefore has no analytical representation. Figure 5 shows an example of the comparison of the exact solution with three moment-based approximations of the convolution integral. The functions convolved in this example were two first-passage-time distributions with means 95 and 220 and Peclet numbers 5 and 29.4, respectively. Note that the approximate solutions, in particular the first-passage-time distribution, resemble well the correct solu-

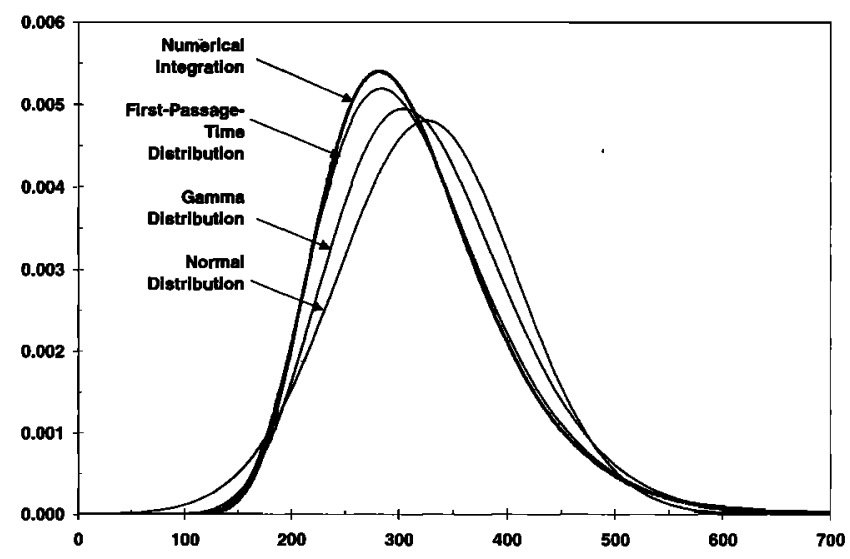

Figure 5. Comparison of the exact solution (numerical integration) with three moment-based approximations of the convolution integral. The functions convolved in this example were two first-passage-time distributions with means 95 and 220 and Peclet numbers 5 and 29.4, respectively. 
tion. Additionally, because the convolution of functions tends to be normally distributed as the number of functions increases [DeGroot, 1986], it is expected that flow path responses will also tend to be normally distributed, thus decreasing their skewness with flow distance. In general, the mean (flow time) and variance (spreading around the mean) of flow path responses increase with flow distance, while their skewness decreases. The first-passage-time distribution not only does satisfy these properties, tending to normal distribution as the flow distance increases, but also its parameters are physically based, and it is defined only for positive values of time.

Assuming the flow path response function is a first-passagetime distribution,

$$
U_{i}(t)=\frac{1}{2 t \sqrt{\pi\left(t / T_{i}\right) / \Pi_{t}}} \exp \left\{-\frac{\left[1-\left(t / T_{t}\right)\right]^{2}}{4\left(t / T_{\imath}\right) / \Pi_{t}}\right\}
$$

where $T_{i}$ is the flow path lag time and $\Pi_{i}$ is the flow path Peclet number that accounts for the spread around the mean of the distribution because of shear and storage effects. $T_{t}$ is the mean value of the distribution, and $\Pi_{t}$ is related to the variance of the distribution. The relation between the first and second moments of the flow path response function $U_{i}(t)$ and of the cell response functions $u_{i}(t)$ is given by [DeGroot, 1986]

$$
\begin{aligned}
E\left(X_{l}\right) & =\sum_{j=1}^{N} E\left(x_{j}\right) \\
\operatorname{var}\left(X_{l}\right) & =\sum_{j=1}^{N} \operatorname{var}\left(x_{j}\right)
\end{aligned}
$$

where $E$ refers to expected value (first moment) and var to variance (second moment around the mean). According to this approach the approximate solution for $U_{z}(t)$ given by (7) would have the same first and second moments as the solution obtained with (4). By equating the first and second moments of $U_{i}(t)$ (given by (7)) to the sum of the moments of the $u_{j}(t) \mathrm{s}$ (given by (6)) the relation between $T_{i}$ and $\Pi_{\imath}$ and $v_{j}$ and $d_{j}$ is found to be

$$
\begin{gathered}
T_{\iota}=\sum_{j=1}^{N}\left(\frac{1}{v_{j}}\right) l_{j} \\
\Pi_{t}=\frac{\left[\sum_{j=1}^{N}\left(\frac{1}{v_{j}}\right) l_{j}\right]^{2}}{\sum_{j=1}^{N}\left(\frac{d_{j}}{v_{j}^{3}}\right) l_{j}}
\end{gathered}
$$

The main advantage of this approach is that it can be applied automatically by using standard functions, like the weighted flow length function, included in commercially available GIS software that operates on raster terrain data. The weighted flow length function allows the user to calculate the distance from one point to another downstream point along a flow path. The function adds the flow length in each cell of the flow path to obtain the total flow length. Besides, the function accounts for the flow direction within the cells so that it assigns a flow length value of 1.00 cell size to cells with flow crossing from one side to the opposite side, a value of 1.41 cell size to cells with flow crossing from one corner to the opposite corner, and a value of 1.20 cell size to cells with flow crossing from one corner to the center and then to the side. Additionally, a grid of weights that multiply the values $1.00,1.41$, and 1.20 , on a cell by cell basis, can be used to calculate a weighted flow length. According to (9) and (10), weight grids calculated as $1 / v$, and $d_{j} / v_{j}^{3}$ can be used to determine the parameters $T_{i}$ and $\Pi_{i}$ of the flow path response function. Originally, weight grids were intended to account for meandering of streams within the cells, and the use of this function for calculating statistical moments of flow responses was developed as part of this model.

The routing model presented in this paper constitutes a general approach to the flow routing problem that allows the modeler to use spatially distributed excess precipitation and hydrologic parameters of the terrain as inputs. The routing model is not bound to any specific methodology for calculating excess precipitation and hydrologic terrain parameters.

The case study presented below shows a way to estimate the excess precipitation and the model parameters for the specific case of a watershed with uniform precipitation, flow velocity, and dispersion coefficient, but different methods can be used depending on the modeler and case study. The spatial variability of the problem is introduced by the nonuniform distribution of excess precipitation as well as the fact that each flow path response has a different average flow time to the watershed outlet and Peclet number.

\section{Case Study: Waller Creek in Austin, Texas}

The runoff routing model was applied to the Waller Creek watershed in Austin, Texas. Waller Creek is a $14.8 \mathrm{~km}^{2}$ watershed located within the urban area of the city of Austin. Two flow-gauging stations, set up by the United States Geological Survey (USGS), are located at 23rd and 38th Streets and have drainage areas of 10.7 and $5.7 \mathrm{~km}^{2}$, respectively. From the flow records it was noticed that the flow peaked first at 23rd Street (downstream) and $\sim 30 \mathrm{~min}$ later at 38th Street (upstream), which goes against intuition because the peak time did not increase with drainage area. Additionally, it was found that for this time period, $88 \%$ of the flow was direct runoff and $12 \%$ was base flow, which is explained by the high impervious cover of urban areas.

Because excess precipitation, flow velocity, and dispersion coefficients were not available for the area, they were estimated by calibration and then used as inputs to the routing model. The model was calibrated with flow records of the station at 23rd Street and verified with flow records of the station at 38th Street. A 3 day period of analysis, subdivided into 15-min duration time steps, was used. The period ranged from October 14, 1994, 7:45 P.M., to October 17, 1994, 6:45 P.M.

The watershed was delineated applying GIS raster functions to a $30 \mathrm{~m} \mathrm{DEM}$ and comprised $\sim 11,900$ grid-cells. A map of the drainage area of the two flow-gauging stations showing the level of development of the land (runoff coefficient map) is presented in Figure 6.

\subsection{Average Excess Precipitation}

Standard engineering practice estimates excess precipitation on the basis of the soil-water balance. Although the soil-water balance is a physically based approach, it has been observed that it might be a complicated process that should account for a large number of parameters, that it is sensitive to the data available, and that it produces results that have to be inter- 


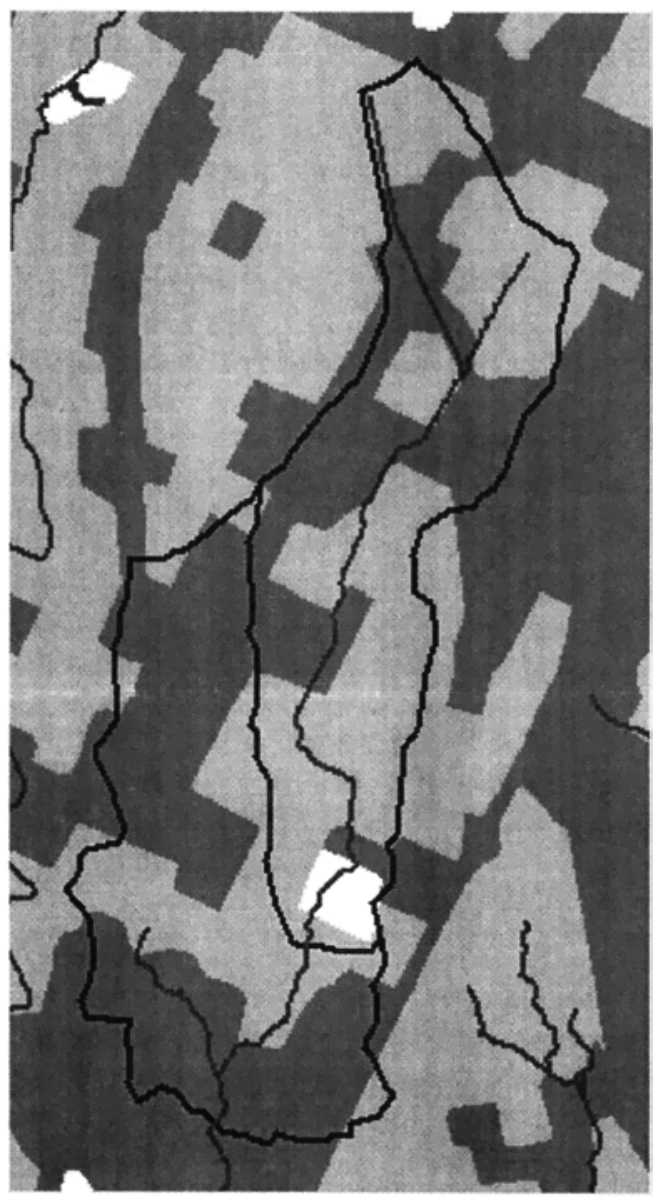

Figure 6. Runoff coefficient map of the Waller Creek watershed. Dark shading corresponds to runoff coefficients $>\mathbf{0 . 4}$, light shading corresponds to values $<0.4$ but $>0.15$, and white corresponds to values $<0.15$. According to our model, only dark shaded areas produced runoff for this period. Thick black lines delimit the drainage area of the flow gauging stations, and thin shaded lines indicate streams.

preted with caution. Willmott et al. [1985], for instance, developed the WATBUG Fortran program that simulates the soilwater balance based on local temperature, precipitation, and soil water-holding capacity. Other excess precipitation models such as the SCS curve number method or just the product of a constant coefficient by the precipitation are examples of attempts of solving the problem. Correct estimation of the excess precipitation though is still far from being achieved.

Because there were not enough data to run a soil-water balance for the Waller Creek watershed, a methodology for determining excess precipitation from flow instead of from precipitation records was developed. Thus, given the flow at a specific station, the method consists of deconvolving the observed flow hydrograph by the watershed response, where the watershed response is estimated from flow records and considers it as a lumped system. Spatial variability of the terrain is considered later in the process of spatial distribution of the excess precipitation.

For determining the watershed response the flow record undergoes a base flow separation, producing time series of runoff flow and base flow. If the runoff flow is plotted against time, a series of curves with unit-hydrograph shape can be observed, which corresponds to the watershed response to isolated storms (more complex curve shapes correspond to combined storms, i.e., long storms with varying intensity, more than one storm in a relatively short period, etc.). For each curve the ordinates are divided by the area under the curve, resulting in the watershed response. In case a long flow record is available, several responses could be determined and averaging their ordinates would lead to a better representation of the watershed response. However, because in the specific case of the 23rd Street station the plot of the flow record, in semilogarithmic scale, showed almost instantaneous peak times followed by straight and parallel recession lines (see Figure 7), the response function was taken as an exponential distribution, i.e., instantaneous peak followed by an exponential recession curve. The parameter of the exponential distribution was set to match the slope of the straight recession lines in the semilogarithmic plot.

The parallel recession lines in Figure 7 also suggest that the watershed responded to all storm events of the 3 day period with the same unit response function. This fact confirms the assumption that a linear approximation is satisfactory for this hydrologic system within this time period because the response did not change from event to event.

To calculate the excess precipitation in the drainage area of the 23rd Street station, the flow record was deconvolved by the watershed response, as is explained below. The relation between the flow hydrograph and the excess precipitation time series for a lumped system was given in (1) and is rewritten here:

$$
Q(t)=A_{w} \int_{0}^{t} I(\tau) \cup(t-\tau) d \tau
$$

where $Q(t)\left[L^{3} T^{-1}\right]$ is the flow hydrograph, $A_{w}\left[L^{2}\right]$ is the watershed area, $I(t)\left[L T^{-1}\right]$ is the excess precipitation, and $\mathcal{U}(t)\left[T^{-1}\right]$ is the estimated watershed response. Determining the excess precipitation consists of solving (11) for $I(t)$, given $A_{w}, Q(t)$, and $U(t)$; in other words, it consists of deconvolving $Q(t)$ by $U(t)$.

Excess precipitation is calculated at discrete time steps (of $15 \mathrm{~min}$ in this example) by trial and error, by guessing values of $I(t)$ for each time step, convolving the guessed $I(t)$ and the previously derived $U(t)$ and multiplying the result by $A_{w}$, and verifying that (11) is satisfied. If (11) is not satisfied, the pro-

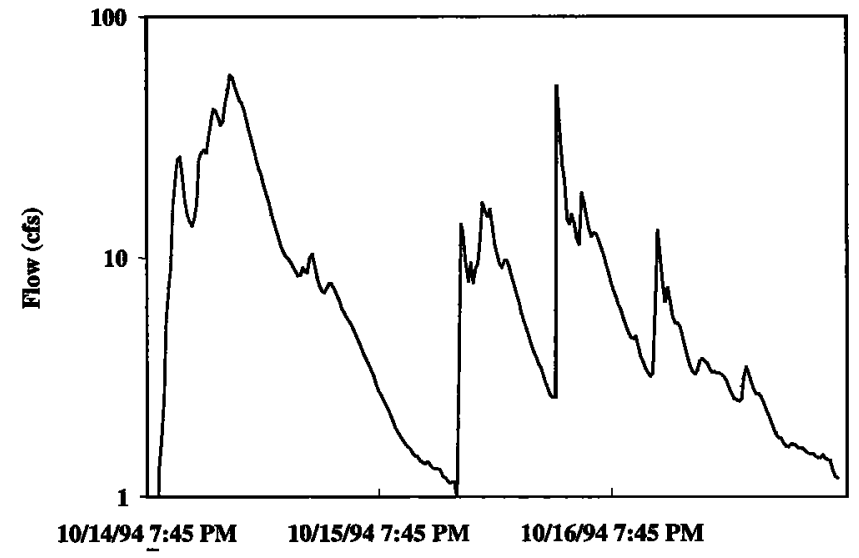

Figure 7. Semilogarithmic plot of the flow in Waller Creek at 23 rd Street. 
cess is repeated with different guessed values of $I(t)$. An optimization routine based on the generalized reduced gradient (GRG2) nonlinear optimization code and included in Microsoft Excel was used in the process of determining the excess precipitation values. The objective function was the sum of the square of the discrepancies between the left-hand side and the right-hand side of (11). Notice that in (11) the time step (i.e., $15 \mathrm{~min}$ ) should be equal to the duration of the input of the response $U(t)$ (i.e., instantaneous), which is not the case. To solve this problem, a $15 \mathrm{~min}$ response function should be derived from the instantaneous response function and then used in the deconvolution process. However, given the approximate methodology used for determining the instantaneous response function, it was assumed that estimating the $15 \mathrm{~min}$ unit hydrograph from the instantaneous response function, rather than just taking the instantaneous response function, would not significantly improve the accuracy of the calculations.

Although from the mathematical point of view deconvolution is an ill-posed problem because the number of unknowns is greater than the number of equations, in this case the deconvolution describes a physical process with which the modeler is familiar. Calculating flow hydrographs as the convolution of excess precipitation and the watershed response is not new in the field of hydrology, and when doing this, one expects the hydrograph to be delayed with respect to the excess precipitation and to be distributed around its centroid with right skewness. Similarly, when deconvolving a hydrograph, excess precipitation is expected to take place as discrete impulses a fixed time before the flow. This piece of information is used to obtain a mathematically and physically correct solution of the deconvolution. In order to ensure a meaningful estimation of the excess precipitation the first set of guessed values of $I(t)$ were taken equal to the flow hydrograph but shifted, to the left in the time axis, by the watershed lagtime (obtained from the watershed response). After running the optimization routine the modified excess precipitation time series minimized the discrepancy between calculated and observed hydrographs and at the same time remained similar in shape to the observed hydrograph, thus ratifying the fact that precipitation and flow are related.

In Figure 8 the calculated excess precipitation and the observed precipitation follow the same trend, although the excess precipitation is about 100 times smaller than the precipitation. It was also observed that the relation between precipitation and excess precipitation is not linear and that large storms tend to generate (even in percentage) more runoff than small storms. Additionally, the excess precipitation and the observed flow also follow the same trend, but in this case the excess

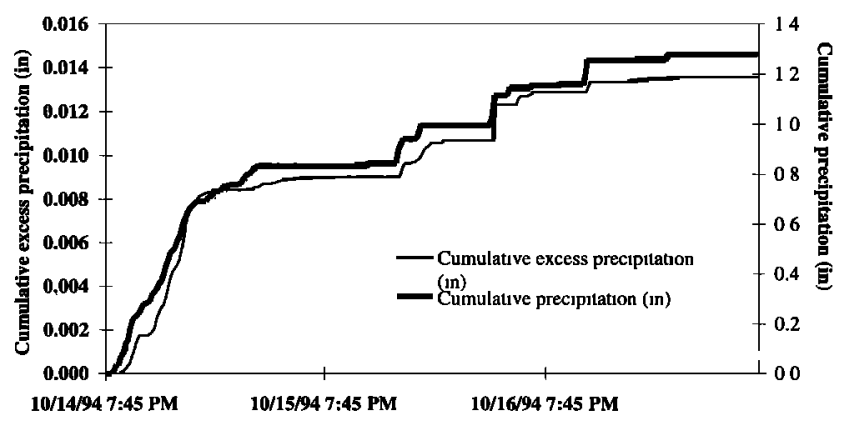

Figure 8. Cumulative precipitation and excess precipitation for the Waller Creek watershed.

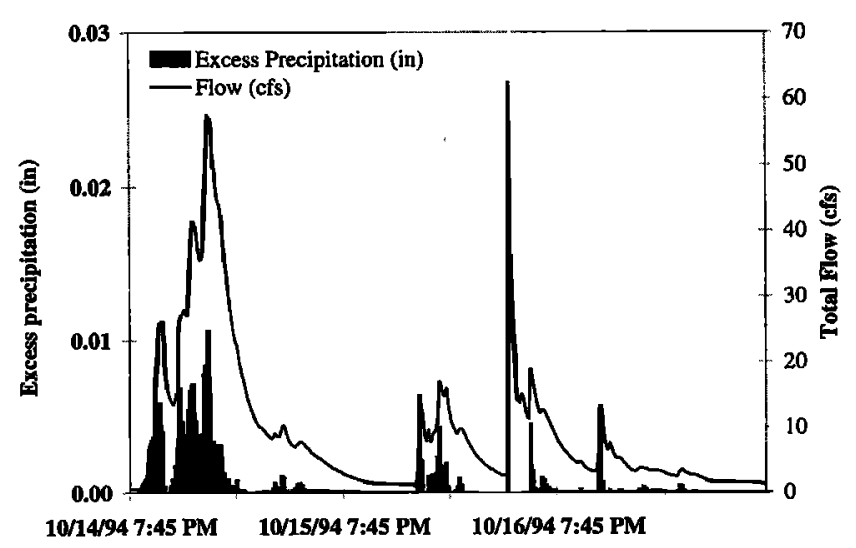

Figure 9. Excess precipitation and total flow for Waller Creek at 23rd Street.

precipitation consists of concentrated pulses, while the flow exhibits short rising limbs followed by long recession curves (see Figure 9).

\subsection{Spatial Distribution of the Excess Precipitation}

Since the flow $Q(t)$ and unit response function $U(t)$ were considered for the watershed as a whole the excess precipitation $I(t)$ obtained by deconvolution is an average value for the entire watershed that should be distributed according to the hydrologic characteristics of the terrain. For the cases in which precipitation can be assumed to be uniform because of the watershed size or because of lack of precipitation data a simplified approach that basis the spatial distribution of excess precipitation on a single parameter, called here the excess precipitation distribution parameter, was considered. Small urban catchments, like Waller Creek, illustrate the case of a small watershed with not enough rainfall data for estimation of precipitation distribution.

The runoff coefficient of the rational formula (i.e., the ratio of the storm hydrograph peak flow per unit drainage area to the storm intensity) was selected as the excess precipitation distribution parameter because its value is strongly related to runoff production, where high values (close to one) correspond to relatively impermeable surfaces that generate much runoff, and low values (close to zero) to permeable areas that generate little or no runoff at all. Additionally, the runoff coefficient can be estimated, on the basis of land use information, from tables available in the literature [Chow et al., 1988; Browne, 1990; Pilgrim and Cordery, 1993]. The selection of the runoff coefficient as the excess precipitation distribution parameter has been influenced by the fact that the rational formula is standard practice for peak discharge estimation when enough detailed data of the watershed are not available. Figure 6 shows a runoff coefficient map of the study area obtained using Browne's [1990] runoff coefficient table. Land use data were provided by the city of Austin, Texas, terrain slope was calculated from the $30 \mathrm{~m}$ DEM, and hydrologic soil group was obtained from the State Soil Geographic (STATSGO) database [SCS, 1994].

However, because the runoff coefficient is just a surrogate for the tendency of the terrain to generate runoff, a correction of the parameter (i.e., a threshold parameter) was introduced in the method therefore generating a new parameter that better relates to the runoff production. Thus excess precipitation in a cell $I_{i}$ is assumed to be directly proportional to the runoff 


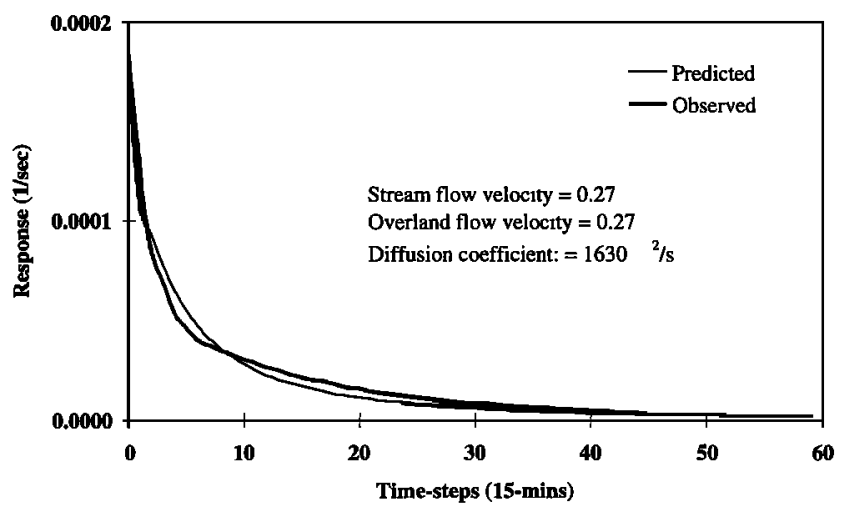

Figure 10. Predicted and observed watershed unit response for Waller Creek at 23rd Street.

coefficient $c_{\imath}$ minus a uniformly distributed and constant threshold parameter $\zeta$ (i.e., $c_{\imath}-\zeta$ or 0 , whichever is greater). This threshold parameter $\zeta$ addresses the fact that some areas might yield no runoff at all for a specific event, depending on rainfall intensity, soil infiltration capacity, or antecedent moisture condition. Values of $c_{i}-\zeta$ for each cell are calculated and used as an excess precipitation scale factor. The excess precipitation generated in a cell $I_{i}(t)$ is given by

$$
I_{i}(t)=\frac{\left(c_{j}-\zeta\right)}{\sum_{j=1}^{N_{w}} \frac{A_{j}}{A_{w}}\left(c_{j}-\zeta\right)} I(t)
$$

where $A_{j}$ is the area of cell $j$ and subscript $i$ refers to the cell where the excess precipitation is being calculated.

To calculate the threshold parameter $\zeta$, the total volume of excess precipitation generated upstream of the 23rd Street station is equated to the total volume that flows at the station, giving

$$
\sum_{t=1}^{N_{23}}\left[\int_{0}^{t_{d}} I_{i}(t) \frac{A_{i}}{A_{w}}\left(c_{t}-\zeta\right) d t\right]=\int_{0}^{t_{t}} Q_{23}(t) d t
$$

where $N_{23}$ is the number of upstream cells, $t_{d}$ is the duration of the hyetograph, $Q_{23}(t)$ is the observed hydrograph, and $t_{f}$ is the duration of the observed hydrograph, all for the 23rd Street station. A threshold parameter of $\zeta=0.4$ satisfied (13). Additionally, $\zeta=0$ was also considered for evaluation of the sensitivity of the model to this parameter.

\subsection{Flow Velocity and Dispersion Coefficient}

To calculate the flow parameters, flow velocity $v$, and dispersion coefficient $d$ (no cell subscript is indicated because both were considered to be uniformly distributed), the watershed unit response was equated to the weighted sum of the flow path responses

$$
\dot{U}(t)=\sum_{i=1}^{N_{w}} \frac{A_{j}\left(c_{i}-\zeta\right)}{\sum_{j=1}^{N_{w}} A_{j}\left(c_{j}-\zeta\right)} U_{\imath}(t)
$$

in which the flow path responses $U_{i}(t)$ depend on the flow parameters. To determine the flow parameters $v$ and $d$, their values are changed until the right-hand side of (14) equals the watershed response $U(t)$ estimated from flow records.

It is not recommended to use this concept for determining spatially distributed flow parameters (i.e., different flow velocity and dispersion coefficient in each grid cell) because it would require an enormous amount of calculations and, more important, would lead to questionable results because of large confidence intervals; in other words, many different combinations of values would satisfy (14). Calculation of the parameters by calibration though leads to reliable results when the number of unknowns, and therefore size of the confidence intervals, is decreased. That is why, for the Waller Creek watershed, the number of parameters was reduced to two: one flow velocity and one dispersion coefficient.

An optimization routine was used to automate the process of changing the values of the flow parameters until the discrepancy between the right- and the left-hand side of the equation was minimized. As before, the optimization routine used was based on the generalized reduced gradient (GRG2) nonlinear optimization code included in Microsoft Excel. In this case the objective function was defined as:

$$
x=\sum o_{t}\left(o_{t}-p_{t}\right)^{2}
$$

where $o_{i}$ is the observed value at time step $i$ (left-hand side of (14)) and $p_{i}$ is the predicted value at time step $i$ (right-hand side of (14)). This objective function differs from the sum-ofsquare errors by the factor $o_{i}$ in each term. This factor was introduced to add extra weight to the points close to the peak flow compared to those in the recession curve. After running the optimization routine it was found that the flow parameters that produced the best match between the observed watershed response and the one obtained as the aggregation of the flow path responses were flow velocity $v=0.27 \mathrm{~m} \mathrm{~s}^{-1}$ and dispersion coefficient $d=1630 \mathrm{~m}^{2} \mathrm{~s}^{-1}$ (see Figure 10).

The estimated excess precipitation and flow parameters can then be extrapolated to other areas if the same hydrologic behavior is assumed. This assumption though might be questionable when the areas used for calibration and application are dissimilar. The values can also be used to estimate flow hydrographs at other locations within the watershed, where hydrologic dissimilarity is less likely to occur.

\subsection{Flow Prediction}

Predicted flow in Waller Creek at 38th Street was determined using the excess precipitation and model parameters obtained for the 23rd Street station. Figure 11 presents ob-

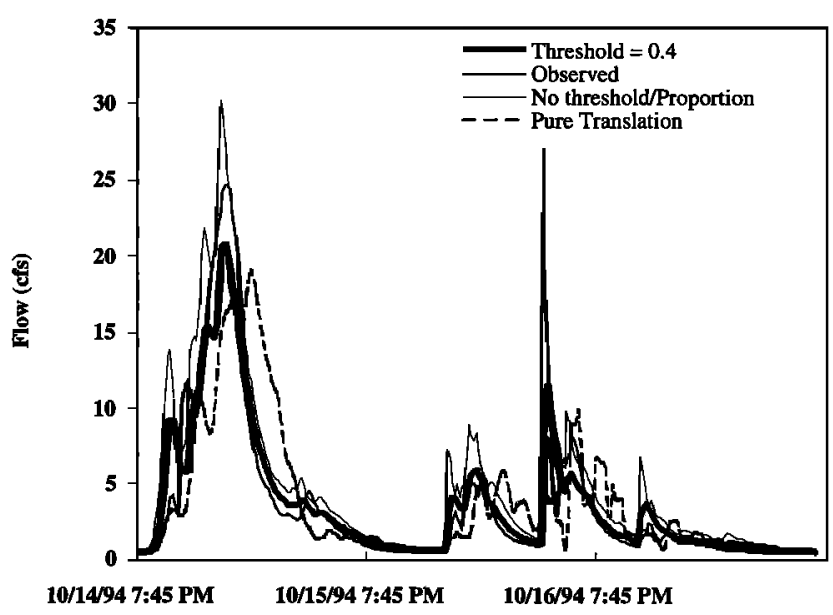

Figure 11. Predicted and observed flow for Waller Creek at 38th Street. 
served flow (labeled Observed) and predicted flow at 38th Street. Four predicted flow series are plotted in Figure 11: the first series (labeled No threshold) assumes a threshold parameter $\zeta=0$; i.e., cell contributions are proportional to the runoff coefficient; the second series (labeled Threshold $=0.4$ ) assumes a threshold parameter $\zeta=0.4$, i.e., cell contributions are proportional to the runoff coefficient minus 0.4 ; the third series (labeled Proportion) is obtained as the flow at 23rd Street multiplied by the ratio of the two drainage areas; and the fourth series (labeled Pure translation) assumes a threshold parameter $\zeta=0.4$ and dispersion coefficient $d=0$. It was interesting to notice that at least for this data set the No threshold series and the Proportion series were almost identical, the difference being negligible for practical purposes. With regard to the No threshold series it was observed that (1) predicted values were consistently higher than observed values, yielding a predicted flow volume that was $41 \%$ greater than the observed volume, and (2) predicted values followed the trend of the observed values but shifted $\sim 30 \mathrm{~min}$ (two time steps) to the left. In the Pure translation series it was observed that (1) predicted flows are shifted $\sim 150 \mathrm{~min}$ (10 time steps) to the left and (2) recession curves are not reproduced well. To a large extent these problems were solved in the Threshold $=0.4$ series. In that case (1) the flow volume error decreased to $4 \%$, (2) the peak times matched and no time-shift was observed, and (3) the recession curves were reproduced well.

The mismatch between the Observed and Pure translation series is explained by the type of response function of a pure translation model, which does not account for fast particles (thus delaying the flow and generating the time shift) and slow particles (thus generating abrupt and short rather than smooth and long recession curves). This mismatch shows the need for considering a parameter, the dispersion coefficient, that models the flow velocity distribution.

Additionally, the fact that the flow at 38th Street is only $39 \%$ of the flow at 23rd Street, instead of 53\% as the ratio of the drainage areas, and the fact that the flow peaks first at $23 r d$ Street and $30 \mathrm{~min}$ later does so upstream at 38 th Street can be explained in the following way: (1) flow at 38th Street is fed by less developed areas than at 23rd Street, and (2) on average, the developed areas that fed Waller Creek at 38th Street are farther from the gauge than those that fed Waller Creek at 23rd Street. This explanation matches the geography of the area and accounts for the peak shift and runoff volume error. This type of hydrologic behavior shows the need to account for the spatial variability of the hydrologic system.

\section{Conclusions}

This research has produced a spatially distributed unit hydrograph method, which differs from previous work by the authors in that it is based on a more complete mathematical framework. The watershed is represented as a grid cell mesh, and routing of water from one cell to the next is accomplished using the first-passage-time response function which is derived from the advection-dispersion equation of flow routing. The runoff from each watershed cell follows a flow path from cell to cell downstream to the watershed outlet. To account for flow routing across each cell, the cell-based response functions are convolved to give a flow path response. An approximate solution to this sequence of convolutions is given by a response function that depends on the mean and variance of the travel time along that path. The watershed response is the sum of the flow path response functions from each cell.

The spatial unit hydrograph method described in this paper uses similar routing functions to those that have been proposed by other authors, but the method by which the overall watershed response is determined is better linked to spatially distributed databases and analysis functions provided by GIS. In particular, the flow path response functions make use of the weighted flow length function in such a way that the response function of each individual cell in the watershed grid is determined from the length of its flow path to the watershed outlet.

The theory presented in this paper is an attempt to generalize the unit hydrograph method for runoff response and to do so on a spatially distributed basis in which the runoff responses from subareas of the watershed are considered separately instead of being spatially averaged. The need for scaleindependent flow routing parameters for calculating flow time (flow velocity) and spreading of a mass slug around its centroid due to shear effects (dispersion coefficient) is presented, and the use of these parameters for better estimation of hydrographs is explained. A methodology for estimating spatially distributed flow parameters though is not proposed in this paper, mostly because flow parameters depend on so many variables that it has not been possible yet to capture them all in a consistent set of rules.

\section{References}

Browne, F. X., Stormwater management, in Standard Handbook of Environmental Engineering, edited by R. A. Corbitt, pp. 7.1-7.135, McGraw-Hill, New York, 1990.

Chow, V. T., D. R. Maidment, and L. W. Mays, Applied Hydrology, McGraw-Hill, New York, 1988.

Clark, C. O., Storage and the unit hydrograph, Trans. Am. Soc. Civ. Eng., 110, 1419-1488, 1945.

DeGroot, M. H., Probability and Statistics, Addison-Wesley, Reading, Mass., 1986.

Lettenmaier, D. P., and E. F. Wood, Hydrologic forecast, in Handbook of Hydrology, edited by D. R. Maidment, pp. 26.1-26.30, McGrawHill, New York, 1993.

Levenspiel, O., Chemical Reaction Engineering, Wiley, New York, 1972.

Littlewood, I. G., and A. J. Jakeman, Characterization of quick and slow streamflow components by unit hydrographs for single- and multi-basin studies, in Methods of Hydrologic Basin Comparison, edited by M. Robinson, Rep. 120, pp. 99-111, Inst. of Hydrol., Wallingford, Engl., U.K., 1992.

Littlewood, I. G., and A. J. Jakeman, A new method of rainfall-runoff modelling and its applications in catchment hydrology, in Environmental Modelling, vol. II, edited by P. Zannetti, pp. 143-171, Comput. Mech., Southampton, Eng. U. K., 1994.

Maidment, D. R., Grid-based computation of runoff: A preliminary assessment, contract DACW05-92-P-1983, Hydrol. Eng. Cent., U. S. Army Corps of Eng., Davis, Calif., 1992a.

Maidment, D. R., A grid-network procedure for hydrologic modeling, contract DACW05-92-P-1983, Hydrol. Eng. Cent., U. S. Army Corps of Eng., Davis, Calif., $1992 b$.

Maidment, D. R., Developing a spatially distributed unit hydrograph by using GIS, in HydroGIS 93, edited by K. Kovar and H. P. Nachtnebel, Publ. 211, pp. 181-192, Int. Assoc. of Sci. Hydrol., Wallingford, Engl., U.K., 1993.

Maidment, D. R., J. F. Olivera, A. Calver, A. Eatherall, and W. Fraczek, A unit hydrograph derived from a spatially distributed velocity field, in Hydrologic Processes, vol. 10, pp. 831-844, John Wiley, New York, 1996a.

Maidment, D. R., F. Olivera, Z. Ye, S. Reed, and D. C. McKinney, Water balance of the Niger Basin, paper presented at North American Water and Environment Congress, Am. Soc. of Civ. Eng., Anaheim, Calif., $1996 \mathrm{~b}$.

Mesa, O. J., and E. R. Mifflin, On the relative role of hillslope and network geometry in hydrologic response, in Scale Problems in Hy- 
drology, edited by V. K. Gupta et al., pp. 1-17, D. Reidel, Norwell, Mass., 1986.

Miller, W. A., and J. A. Cunge, Simplified equations of unsteady flow, in Unsteady Flow in Open Channels, edited by K. Mahmood and V. Yevjevich, vol. 1, chap. 5, Water Resour. Publ., Fort Collins, Colo., 1975.

Naden, P. S., Spatial variability in flood estimation for large catchments: The exploitation of channel network structure, J. Hydrol. Sci., $37,53-71,1992$.

Nash, J. E., The form of the instantaneous unit hydrograph, $L A H S$ Publ. 45, 114-121, 1957.

Nauman, E. B., Residence time distributions in systems governed by the dispersion equation, Chem. Eng. Sci., 36, 957-966, 1981.

Olivera, F., Spatially distributed modeling of storm runoff and nonpoint source pollution using geographic information systems (GIS), Ph.D. dissertation, Dep. of Civ. Eng., Univ. of Tex. at Austin, 1996.

Olivera, F., and D. R. Maidment, Runoff computation using spatially distributed terrain parameters, paper presented at North American Water and Environment Congress, Am. Soc. Civ. Eng., Anaheim, Calif., June 22-28, 1996.

Olivera, F., D. R. Maidment, and R. J. Charbeneau, Non-point source pollution analysis with GIS, paper presented at Spring Meeting, Am. Soc. Civ. Eng., Tex. Sect., Waco, Tex., April 26-28, 1995.

Pilgrim, D. H., Travel times and nonlinearity of flood runoff from tracer measurements on a small watershed, Water Resour. Res., 12, 487-496, 1976.

Pilgrim, D. H., and I. Cordery, Flood runoff, in Handbook of Hydrol- ogy, edited by D. R. Maidment, pp. 9.1-9.42, McGraw-Hill, New York, 1993.

Rodriguez-Iturbe, I., and J. B. Valdes, The geomorphologic structure of hydrologic response, Water Resour. Res., 15, 1409-1420, 1979.

Soil Conservation Service (SCS), National Engineering Handbook, sect. 4, Hydrology, U. S. Dep. of Agric., Washington, D. C., 1985.

Soil Conservation Service (SCS), STATSGO-State Soil Survey Geographic Data Base [CD-ROM], U. S. Dep. of Agric., Washington, D. C., 1994.

Troch, P. A., J. A. Smith, E. F. Wood, and F. P. de Troch, Hydrologic controls of large floods in a small basin, J. Hydrol., 156, 285-309, 1994.

Vieux, B. E., Geographic information systems and non-point source water quality and quantity modeling, Hydrol. Proc., 5, 101-113, 1991.

Vicux, B. E., DEM aggregation and smoothing effects on surface runoff modeling, J. Comput. Civ. Eng., 7, 310-338, 1993.

Vieux, B. E., and S. Needham, Nonpoint-pollution model sensitivity to grid-cell size, J. Water Resour. Plann. Manage., 119, 141-157, 1993.

Willmott, C. J., C. M. Rowe, and Y. Mintz, Climatology of the terrestrial seasonal water cycle, J. Climatol., 5, 589-606, 1985.

D. Maidment and F. Olivera, Center for Research in Water Resources, J. J. Pickle Research Campus 119, University of Texas at Austin, Austin, TX 78712. (folivera@mail.utexas.edu)

(Received August 10, 1998; revised November 23, 1998; accepted November 24, 1998.) 